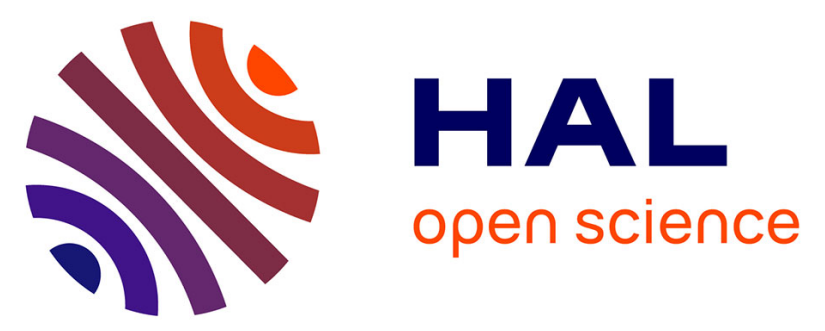

\title{
A novel "Correlated Ion and Neutral Time Of Flight" Method: event-by-event detection of neutral and charged fragments in Collision Induced Dissociation (CID) of mass selected ions
}

C. Teyssier, R. Fillol, H. Abdoul-Carime, B. Farizon, M. Farizon, T.D. Märk

\section{To cite this version:}

C. Teyssier, R. Fillol, H. Abdoul-Carime, B. Farizon, M. Farizon, et al.. A novel "Correlated Ion and Neutral Time Of Flight" Method: event-by-event detection of neutral and charged fragments in Collision Induced Dissociation (CID) of mass selected ions. Review of Scientific Instruments, 2014, 85, pp.015118. 10.1063/1.4863015 . in2p3-00932141

\section{HAL Id: in2p3-00932141 \\ https://hal.in2p3.fr/in2p3-00932141}

Submitted on 16 Jan 2014

HAL is a multi-disciplinary open access archive for the deposit and dissemination of scientific research documents, whether they are published or not. The documents may come from teaching and research institutions in France or abroad, or from public or private research centers.
L'archive ouverte pluridisciplinaire HAL, est destinée au dépôt et à la diffusion de documents scientifiques de niveau recherche, publiés ou non, émanant des établissements d'enseignement et de recherche français ou étrangers, des laboratoires publics ou privés. 
A novel "COrrelated Ion and Neutral Time OfFlight" Method: event-by-event detection of neutral and charged fragments in Collision Induced Dissociation (CID) of mass selected ions

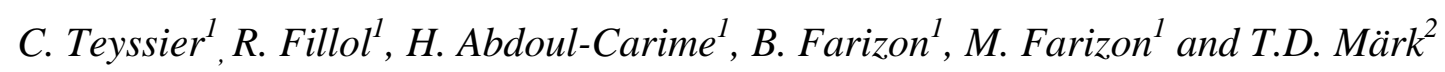

\begin{abstract}
A new mass spectrometricMS-MS method based on Time Of Fight measurements performed on an event-by-event detection technique is presented. This "COrrelated Ion and Neutral Time of Flight (COINTOF)" method allows to exploreCID fragmentationprocesses by directly identifying not only all ions and neutral fragments produced but also their arrival time correlations within each single fragmentation event from a dissociating molecular ion. This constitutes a new step in the characterization of molecular ions. The method will be illustratedhere for a prototypical case involvingCollision Induced Dissociation (CID)of protonated water clusters $\mathrm{H}^{+}\left(\mathrm{H}_{2} \mathrm{O}\right)_{\mathrm{n}=1-5}$ upon collisions with argon atoms.
\end{abstract}

${ }^{1}$ Université de Lyon, F-69003, Lyon, France; Université Lyon 1, Villeurbanne; CNRS/IN2P3, UMR5822, Institut de Physique Nucléaire de Lyon; F-69622, Villeurbanne.

${ }^{2}$ Institut für Ionenphysik und Angewandte Physik, Leopold Franzens Universität Innsbruck, Technikerstrasse 25, A-6020 Innsbruck, Austria 


\section{Introduction}

Mass spectrometry is nowadays a standard technique used in many fundamental and applied areas of science. As an analytical technique, it is used in diverse fields such as for the detection of drugs $^{1}$ in forensic applications, for the controllingof processes ${ }^{2}$ in food production, or for the analysis during microchips manufacturing processes ${ }^{3}$ in the field of nanotechnology.One analytical method in mass spectrometry involves Collision Induced Dissociation (CID) where a primary molecular ion dissociates into secondary fragments after collision with a gas target. Indeed, the CID technique isalso a powerful tool in physics and chemistry to shed light onthe nature of ion collision reactions present in many fundamental and technical phenomena (e.g., interstellar media, planetary ionospheres, plasmas). Moreover, it is widely applied in analytical chemistry to elucidate the identity and the nature of molecular and cluster ions via MS/MS spectrometry ${ }^{4}$. Although so far limited to the detection and identification of the produced ion fragments in recent studies it has been extended to the analysis of ions formed in single events ${ }^{5}$ or to the detection of neutrals species ${ }^{6}$. Nevertheless directly monitoring all ionized and neutral fragments produced and their correlations within a single fragmentation event - as will be described in the following- is a major step towards the complete description of the physics and chemistry of the reaction.

Here a new type of mass spectrometry technique, namedCOINTOF (OㅏrelatedIon and Neutral Time OfFlights) mass spectrometry developed in our laboratory ${ }^{7}$ is presented.This method allows the exploration offragmentationprocesses by recording all ionized and neutral productsin a single dissociation event of an individual precursor ion. Detailed information on the physics of the dissociation process is obtained by a statistical analysis of an ensemble of 
recorded events. This new method is illustrated in the following forthe case of CID of protonated water cluster ions.

\section{Principle of the COINTOF method}

The principle of the method is presented in Figure 1. As the COINTOF technique is a part of an MS-MS technique, a prerequisite to COINTOF is the production of a mass and energy selected beam of parent (precursor) ions. This production of an intense mass and energy selected ion beam has been thoroughly described elsewhere ${ }^{8}$. Briefly, protonated water clusters are produced by electron impact in a supersonic nozzle expansion of water vapor. They are accelerated to an energy between 2 to $8 \mathrm{keV}$ and mass selected by a double focusing sector field mass spectrometer ${ }^{9}$. For the present CID experiment, the energy and massselected $\mathrm{H}^{+}\left(\mathrm{H}_{2} \mathrm{O}\right)_{\mathrm{n}}$ beam crosses an effusive argon gas jet whose density is controlled in such a way as to insure single collision conditions in the CID region. It is noteworthy however, that the precursor ions can collide with other type of particles (protons, ions, electrons or photons) at the collision point.The newly designed time of flight COINTOF apparatus is mounted right after the collisionregion along the direction of the incident beam as shown in Fig. 1. A single dissociative collision of a $\mathrm{H}^{+}\left(\mathrm{H}_{2} \mathrm{O}\right)_{\mathrm{n}}$ parent ion with an $\mathrm{Ar}$ atom will in general produce a daughter ion and one or more neutral fragments. This daughter ionis then extracted from the collision area and accelerated through $1.8 \mathrm{kV}$ before reaching a field free time of flight TOF zone.Neutral fragments emerging from the collision zone however will not be affected by this acceleration field and remain after the collision close tothe initial velocity of the parent ion (except for small changes due to additional kinetic energy released in the collision process itself, see below). All the fragments (ionized and neutral) are then detected by the one Micro Channel Plate detector (MCP, Hamamatsu) with the charged fragment arriving significantly 
earlier than the neutral species. The MCP set-up is designed to ensure the collection/detection of all the fragments by this detector. The signals produced are sampled by a fast Analog to Digital Converter (ADC8 GHW/10bits fromAcqiris ${ }^{\circledR}$, Agilent) and it is recorded without dead time during a given arrival time window. The intensity of the initial parent ion beam is controlled in such a way as to ensure that only the fragments of one single parent ion can reach the detector during the acquisitiontime window. Therefore, the correlation between the arrival times of the charged and neutral fragments resulting from the dissociation of one single parent ion can be recorded. This correlation is determined consecutively for a large number of dissociation events.

\section{Description of the COINTOF detector}

The COINTOF detector is based on theWiley-McLarentype ${ }^{10}$ timeofflight principle.Itconsistsofthreeseparatezoneswith different values of electric fields(see Figure 1).Thefirstzoneis theextractionzone andthesecondthe acceleration zone.Thecollision induced dissociation takes placeatthecenteroftheextraction zonethat is the crossing point between the cluster ion beam and the neutral target beam. In the present CID experiments argon or helium is used as a neutral target gas and theneutral gas jet has a maximum extent of $2 \mathrm{~mm}$ at the crossing point ${ }^{11}$.Since all fragments (neutral and ionized) produced after dissociation have a velocity close to the velocity of the parent ion, the use of an extraction voltage is a priori not a mandatory requirement. Nevertheless the charged products are extracted by an electric field applied and after reaching the acceleration zone accelerated further by an acceleration field produced bya series of electrodes which provide ahomogenous electric field in this zone. 
Therefore any charged specieswill be accelerated by the same electric field and thus acquire on top of the initial velocity an additional velocity characteristic of its mass/charge ratio.

After this acceleration zone, all species travel through afield free time of flight zone before reaching the MCP detector.This TOF zoneconsists of a drift tube of $150 \mathrm{~mm}$ length held at the acceleration potential.Detection is carried out with a MCP detector operated with a difference voltage of $1700 \mathrm{~V}$ and positioned $40 \mathrm{~mm}$ behind this field free zone. In the present casewe used a pair of MicroChannel Plates(MCP-F4293-07-Hamamatsu) with an effective area of $20 \mathrm{~mm}$ in diameter and with channel diameters of $12 \mu \mathrm{m}$ mounted in a Chevronlike fashion. The MCP signal is collected on a single anode. It should be noted that this anode can be replaced by wire anodes, to determine the exact position of impact of the collision products on the detector.

One of the key points in the COINTOF technique is that the parent ions, in the present case protonated water cluster ions, have an energy prior to collision of $2 \mathrm{keV}$ up to $8 \mathrm{keV}$ and this high energy ensures that after fragmentation both ionized and neutral products are detectable on the detector because both will lead upon collision at the entrance plate of the MCP to the emission of secondary electrons which are then amplified by the channel plates. It must be underlined though that neutral products are notaccelerated after the interaction zone while the charged species receive an additional energy due to acceleration in the electric field applied. The velocity of the neutral products is close to the velocity of the parent ion. Neverthelessthe neutral products from the parent ion reach the detector with sufficient energy (at least $2 \mathrm{keV}$ ) to be detected and they are well separated in their arrival time from the ionized fragments which are arriving much earlier due to the additional energy drawn from the accelerating field. It is clear that the present technique is limited to studies where the 
initial collision energy is at least $2 \mathrm{keV}$, because below this energy the efficiency for emission of secondary electrons at the entrance plate of the MCP is too small.

\section{Simulation of the COINTOF geometry}

Thenecessary geometryofthepresent timeofflight set-upand the corresponding trajectoriesofthe particles has been calculatedusing the charged particleoptics simulationsoftware,SIMION ${ }^{12}{ }^{12}$.Figure 2 showsthepresent COINTOF detector simulated bySIMION®showingtheequipotentiallines(inblue)in the three different zones and voltages applied.As mentioned above the produced ions and neutrals will have after the collision the velocity of the parent ion that is they will have a kinetic energy in proportion of their mass to the mass of the parent ion. These fragment kinetic energies will be modified in case of ionized fragments by the accelerating field and in addition by the kinetic energy released (KER)during the fragmentation process.This KER may amount to up to several $100 \mathrm{meV}^{13}$ (i.e., typical $\mathrm{H}$ bond energies). This energy ishowever negligibleto a first approximationin comparison to thekineticenergyofthefragments(fractionofkeV) and the energy gained by the accelerating field $(1.8 \mathrm{keV})$. Nevertheless, this additional KER will lead to an additional broadening of the measured distribution of the time difference between the arrival times of the ionized and the neutral products. On the other hand, the mean time difference between ionized fragment and the neutral fragments is directly related to the mass of the ionized(and accelerated) fragment.

SIMION®simulations were carried outforvariousion massesanda range of energies.Thesesimulationsprovide the arrivaltimesonthe MCP detectorforeachionandcorresponding neutralfragmentseparately.Table1presentsresultsforfragmentsfrom different parent ionsall at 
the

$$
\text { sameparentvelocityof }
$$

thetimeofflightsfortheneutralfragmentsareindependentoftheirmass since the applied electric fields have no influence on their flight times, in contrast to that of the ions.Thedifferencesintimesbetweenchargedandneutral(lastcolumn)depend onthemassofthecharged fragment and thus allowtheidentificationofthe chargedfragment for each dissociation event.

\section{The acquisition set up}

The output signal generated by the impact of neutral and ionized fragments on the MCP detector is connected to an acquisition devicevia preamplifiers (FAMPS8, HandelsRoentdek $\mathrm{GmbH}$ ). During the measurements carried out to validate the present method, two acquisition chains are installed in parallel as shown in Figure 3:

- The"TDC multihit" acquisition line consists of a constant fraction discriminator, a TDC (Time Digital Converter) module and a fast bus (ECL) for transferring the time values in a memory. The unit is managed by standard CAMAC. The TDC module allows multi-hits to record with a time resolution of $0.5 \mathrm{~ns}$, however with a dead time of $15 \mathrm{~ns}$ between successive pulses. It is programmed inthe "common stop" mode. In this mode the time of arrival of the various fragments produced by the dissociation of a given precursor is savedand labeled as the arrival times corresponding to the dissociation of the corresponding precursor ion. This acquisition line provides a directCOINTOF mass spectrum of the charged fragments obtained in continuous operation without an external trigger (CID-recorded COINTOF spectrum). Figure 3shows such a CID mass spectrum for the case of $8 \mathrm{keVprotonated} \mathrm{water} \mathrm{tetramer}$ 
parent ions interacting with argon target gas. It is noteworthy that the COINTOF mass spectrum differs from that obtained traditionally, where the charged species are plotted as a function of the mass to charge ratio. In the COINTOF mass spectrum, the ions are plotted as a function of the difference between the arrival instant of the neutral and the ion, $\Delta \mathrm{T}$. Since the neutral species remain at the velocity of the precursor (to a first approximation), they can be used as an intrinsic time reference within a single dissociation event. Thus the lighter the ion species, the larger is $\Delta \mathrm{T}$, as shown in fig.3 (lower right side) where the four mass peaks refer toH $\mathrm{H}^{+}\left(\mathrm{H}_{2} \mathrm{O}\right)_{3}, \mathrm{H}^{+}\left(\mathrm{H}_{2} \mathrm{O}\right)_{2}, \mathrm{H}^{+}\left(\mathrm{H}_{2} \mathrm{O}\right)_{3}$ and $\mathrm{H}^{+}$from left to right respectively.

- The "ADC-signal SID" acquisition line uses a 10-bit analog to digital converter, coupled to a memory 8GHz Quick Access 1.2 MB (Acqiris map). The PCI card is connected to a standard PC computer.Recording of the detected signal is performed on an event by event basis. Within a single event, in contrast to the TDC line, there is no dead time.For each dissociationthe signal is recorded individually as shown in Fig.3. By summing up these individual signals this acquisition linecan also produce a COINTOFmass spectrum of charged fragments as in case of using the TDCmultihitacquisition line but in this mode more information can be deduced from the data. By choosing an appropriate time window,it is possible to record onlyspecificdissociation events.

From these data we can immediately deduce the number of products for a given precursor ion. The precursor ions arriveone after the other in the interaction zone at a rate of typically one ion per $1 \mathrm{~ms}$ (i.e., $1000 \mathrm{cps}$ ). On the other hand, the acquisition time window is about two to four microseconds. Therefore on average there is no overlap between successive dissociation events and the number of peaks can be directly related to the reaction under 
study. In the example shown in Figure 3, three products are detected for the tetramer parent ion, i.e., a charged product and two neutral fragments. Indeed, thecharged product from the precursor, which has been accelerated,hitsthe detector before the two neutral products from the same precursor. Moreover, the acquisition set upincludes a series of signal triggering modulesthus allowing us to select a specific (adjustable) acquisition timeafter the first (neutral) product of interaction hits the detector. Moreover the duration of the acquisition window is adjustable. This allows making specific measurements, for example, using acquisition strategies reducing the acquisition time.

The present acquisition set-up also allows the recording of the amplitude of the detected signal as shown in Figure 4foran example utilizingthe ADC converter line.The amplitude of the detected signal is digitized into 10 bits at a rate of 8 gigahertz (125ps). For each event, the shape of the detection pulse is also recorded. The acquisition device is organised in such a way as to label the set of numbers obtained for a given precursor as an event associated with the interaction of this one precursorwith the target. This labelling step allows to distinguish information acquired (arrival time and magnitude of the peaks) between different precursors, thereby preserving the correlation between information obtained for eachevent. It should be noted that without an external time reference, this approach enables us to work with a continuous beam of precursor ions of strong intensity and to have a highrate of repetition. Typically, we carry out experiments with MCP intensities of 500counts/s. The acquisition time window is about a couple of $\mu$ s thus allowing us to record event after event.

\section{CID of protonated water cluster ions explored bythe COINTOF Method: a test case}


The COINTOF method can be applied to a wide range of molecular ions. As a test case, we present here results obtained for collision induced dissociation of protonated water cluster $\left(\mathrm{H}_{2} \mathrm{O}\right)_{\mathrm{n}=2-5} \mathrm{H}^{+}$withan argon target beam. All parent cluster ions studied here are accelerated to energies corresponding to the velocity of $130.10^{3} \mathrm{~m} / \mathrm{s}$ and mass selected by an ExB sector field mass spectrometer. Collision induced dissociation of these cluster ions at this velocity leads to the production of $\left(\mathrm{H}_{2} \mathrm{O}\right)_{n-1} \mathrm{H}^{+}, \ldots\left(\mathrm{H}_{2} \mathrm{O}\right) \mathrm{H}^{+}$and $\mathrm{H}^{+}$charged fragments which are usually accompaniedbythe loss of one or several neutral water molecules from the precursor ion.

Two prototypical examples of recorded single dissociation event signals are given in Fig. 5 for CID of the protonated dimer. Each arrival time window is associated with the dissociation of one single $\mathrm{H}^{+}\left(\mathrm{H}_{2} \mathrm{O}\right)_{2}$. Due to the acceleration zone after the collision, the first peak in each time window is attributedto the charged fragment. The arrival time for the neutral fragments is always larger than any of that of the charged fragments. Moreover, the difference $\Delta \mathrm{T}$ between the arrival time of the charged fragment(s) and the neutral one(s) is directly related to the mass to charge ratio(s) of the ionized fragments involved.

In Figure 5A, $\Delta \mathrm{T}$ is characteristic of the $\mathrm{H}^{+}\left(\mathrm{H}_{2} \mathrm{O}\right)$ ion and by comparison with the ion trajectory simulations the underlying dissociation event corresponds to

$$
\mathrm{H}^{+}\left(\mathrm{H}_{2} \mathrm{O}\right)_{2} \rightarrow \mathrm{H}^{+}\left(\mathrm{H}_{2} \mathrm{O}\right)+\mathrm{H}_{2} \mathrm{O}
$$

In contrast, three peaks are observed in the time arrival window shown in Figure 5B, corresponding to one charged fragment and two neutral fragments. The difference in arrival times between the charged and neutral fragments is characteristic of the $\mathrm{H}^{+}$ion. Thus this arrival time spectrum indicates the dissociation of the protonated dimer in three fragments, the proton and two neutral water molecules via reaction 


$$
\mathrm{H}^{+}\left(\mathrm{H}_{2} \mathrm{O}\right)_{2} \rightarrow \mathrm{H}^{+}+\mathrm{H}_{2} \mathrm{O}+\mathrm{H}_{2} \mathrm{O}
$$

Note that thearrival time difference between the two neutral fragments (caused by different KER values of the two fragments) may besmaller than the typical dead time of discriminators used in standard arrival time measurements with a time to digital converter.Nevertheless, in the present case it is accessible by the useof a fast ADC.

The examplepresented in Figure 6involving CID of the protonated water pentamerillustratesvarious steps in a particular analysis. In the left upper insert we show thespectrum of the charged fragments forCID of $8 \mathrm{keV}\left(\mathrm{H}_{2} \mathrm{O}\right)_{5} \mathrm{H}^{+}$with argon as target gas. Each $\Delta \mathrm{T}$ (ns) peak is associated to a given mass to charge ratio(s) for aspecific charged fragment produced in the collision event (see Table 1), corresponding to the detection of $\mathrm{H}^{+}\left(\mathrm{H}_{2} \mathrm{O}\right)(19 \mathrm{amu}-\Delta \mathrm{T} \approx 490 \mathrm{~ns}), \mathrm{H}^{+}\left(\mathrm{H}_{2} \mathrm{O}\right)_{2}(37 \mathrm{amu}-\Delta \mathrm{T} \approx 312 \mathrm{~ns}), \mathrm{H}^{+}\left(\mathrm{H}_{2} \mathrm{O}\right)_{3}(55 \mathrm{amu}-\Delta \mathrm{T} \approx 230 \mathrm{~ns})$ and $\mathrm{H}^{+}\left(\mathrm{H}_{2} \mathrm{O}\right)_{4}(73 \mathrm{amu}-\Delta \mathrm{T} \approx 182 \mathrm{~ns})$ fragments. In the lower insert right hand side, a single event for the dissociation channel of $\left(\mathrm{H}_{2} \mathrm{O}\right)_{5} \mathrm{H}^{+}$into $\left(\mathrm{H}_{2} \mathrm{O}\right)_{3} \mathrm{H}^{+}+2\left(\mathrm{H}_{2} \mathrm{O}\right)$ is reported; three peaks are observed, the first one corresponding to the ionized fragment and the two close peaks at higher arrival times corresponding to the twoneutral water units. Figure 6 shows also the most stable protonated water pentamer structure from theoretical calculations of Miyazaki et al. ${ }^{14}$. After collision the excess energy can lead to various dissociation channels with two neutralsubunitsthat can arise from any site of the $\mathrm{H}^{+}\left(\mathrm{H}_{2} \mathrm{O}\right)$ central ion. Nevertheless, the measurement of the time differencebetween the two neutral water subunits $(\approx 31.3 \mathrm{~ns})$ will be a key information regarding the structure of the decaying parent ion.

In addition CID experiments have been performed here with protonated water cluster ions $\mathrm{H}^{+}\left(\mathrm{H}_{2} \mathrm{O}\right)_{\mathrm{n}}$ for sizes $\mathrm{n}$ from 1 up to 5 all at a velocity of $130.10^{3} \mathrm{~m} / \mathrm{s}$. In Figure 7 we show the mass spectra of the respective charged fragmentsobtained by the COINTOF method. The 
arrival time of the first neutral fragment is used as a time reference to identify the charged fragments for each dissociating precursor ion $\mathrm{H}^{+}\left(\mathrm{H}_{2} \mathrm{O}\right)_{n}$ using the results obtained with the SIMION simulation (Table 1). The red asterisksin Figure 7 correspond to the values obtained with the SIMION calculations. On the right hand sideof Figure7the various dissociation channelspresent in the mass spectra are listedfor each incident precursor ion $\mathrm{H}^{+}\left(\mathrm{H}_{2} \mathrm{O}\right)_{n}$. As expected the charged fragments observed correspond to the loss of one up to $n \mathrm{H}_{2} \mathrm{O}$ molecules. Nevertheless differences are observed concerning the abundance of the various $\mathrm{H}^{+}\left(\mathrm{H}_{2} \mathrm{O}\right)_{\mathrm{p}}$ productions formed by these collisions. The most surprising result is the therelative large abundance of the $\mathrm{H}_{3} \mathrm{O}^{+}$fragment ion among the fragment ions produced in the protonated water pentamer case. This may be understood however by the important role ofthe $\mathrm{H}_{3} \mathrm{O}^{+}$ion (Eigen ion) as the central core of protonated water clusters as discussed in numerous papers and shown experimentally by Headricks et al. ${ }^{15}$ in infrared spectra of $\mathrm{H}^{+}\left(\mathrm{H}_{2} \mathrm{O}\right)_{n}$ clustersfor specific small cluster sizes. The present results on the water pentamer ionssuggest that the parention structure seems in accordance with a $\mathrm{H}_{3} \mathrm{O}^{+}$ion (Eigen) core surrounded by $\mathrm{H}_{2} \mathrm{O}$ molecules as calculated by Miyazaki et al. ${ }^{14}$ (see Figure 6).

\section{Conclusion}

In conclusion, the novel CID mass spectrometry technique, COINTOF, presented here provides compared to earlier studies a more detailed description of a collision induced dissociation process by directly probing not only all ionized and neutral fragments produced but also their correlations in time within each single dissociative event. This COINTOF method is implemented on DIAM ${ }^{1}$, a recentlydesigned experimental setup at University Lyon 1 to investigate processes resulting from the irradiation of various molecular nanosystems. This new MS/MS spectrometer detects neutral and charged fragments arising from the 
dissociation of a single precursor ion. The set up does not need any prior external time reference and can be operatedin a continuous mode. The "event by event" recording allows to analyzeCID reactions beyond the sole average production rate of charged fragments. This technique allows the correlated measurements of the time of flights of charged and neutral fragments produced within the same dissociation event of a mass and energy pre-selected molecular parent ion. The power of this COINTOF technique is illustrated here showing examples from collision induced dissociation of protonated water cluster ions with atomic gas targets (e.g. argon). 


\section{FIGURES}

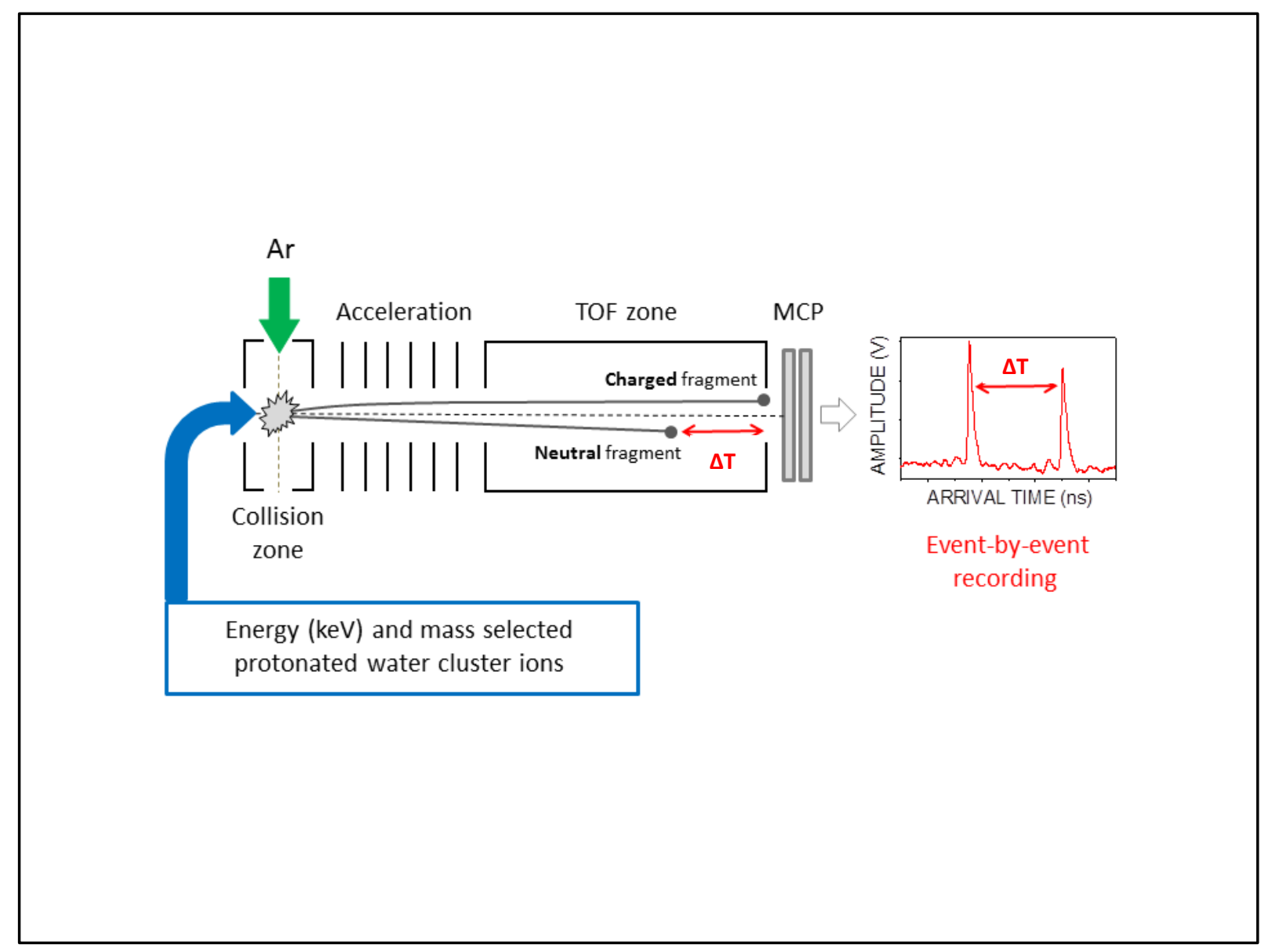

Figure 1: Principle of the COINTOF method. The mass and energy selected precursor ions collide, here, with Ar atoms. The ionized fragments are extracted from the collision zone and accelerated before reaching a field free zone. The neutral species are not influenced by these electric fields. All the fragments resulting from the dissociation of a single precursor ion hit the detector, and the associated signalsare recorded. 


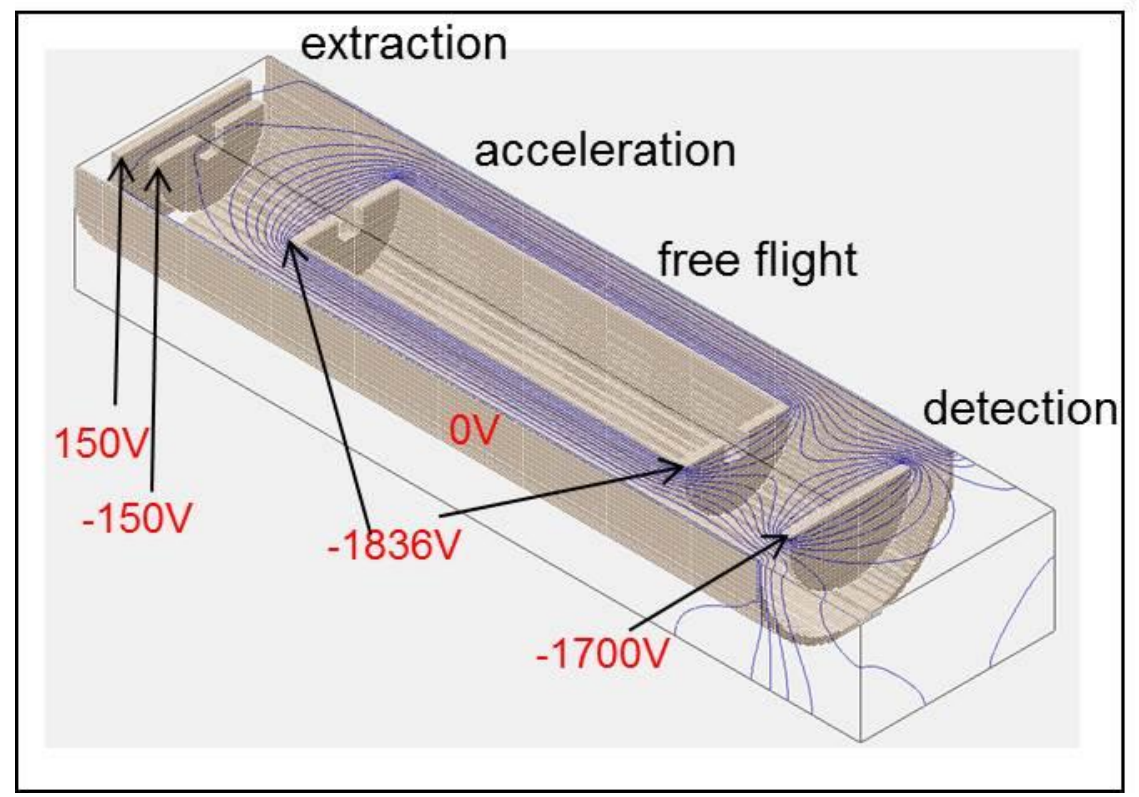

\section{Figure2:}

Simulation of the COINTOF geometryby SIMION ${ }^{\odot}$ software.Three zones corresponding to the extraction, the acceleration and the free flightpart are representedwith their typical applied voltages. Theequipotentiallinesare drawninblue. 


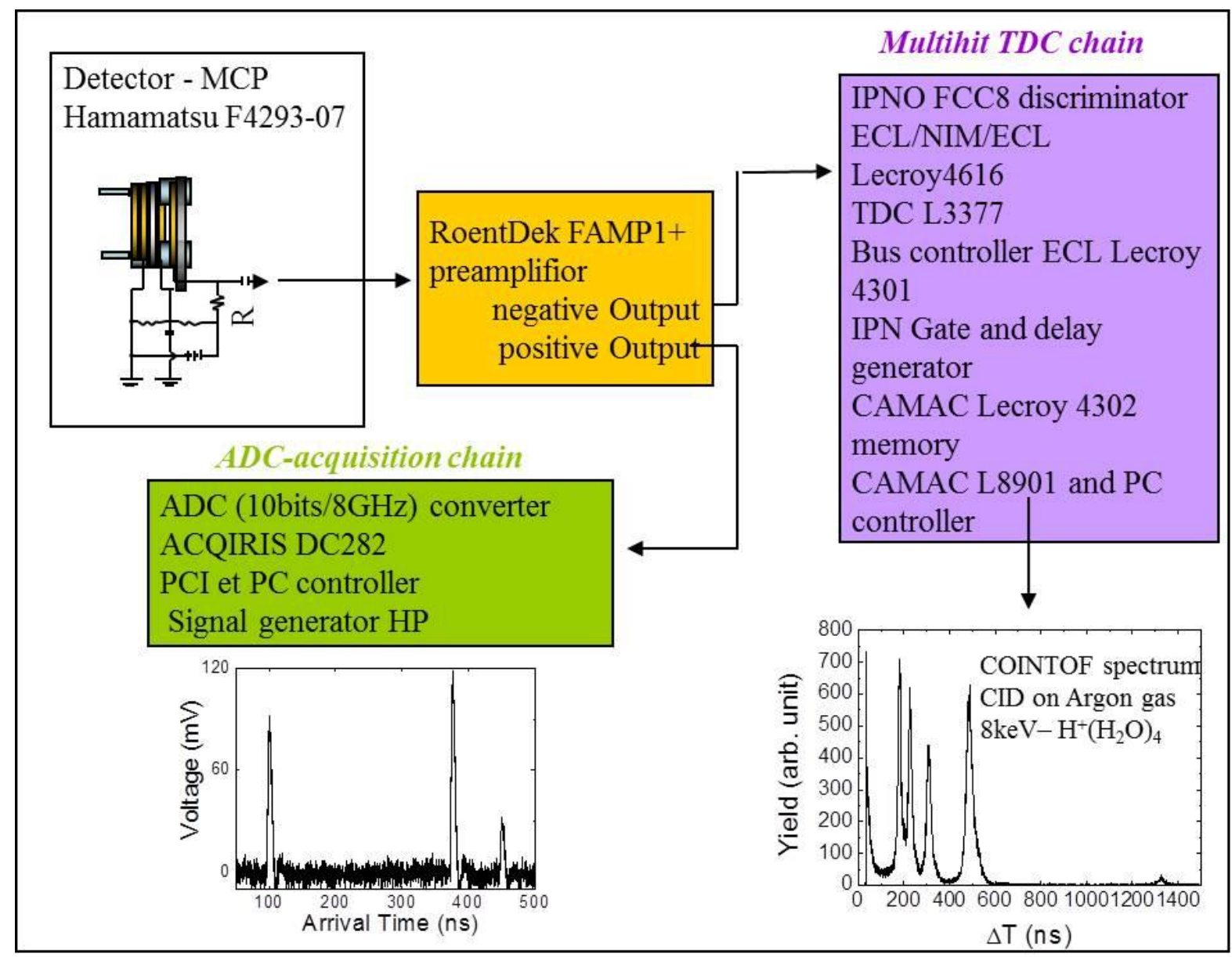

Figure 3: Principle of the acquisition set-ups used. Two acquisition lines have been used in parallel. The TDC-multihit chain providesthe COINTOFmass spectra (right hand side). The ADC (10bits/8GHz)acquisition chain is used to record an arrival time spectrum for a single dissociation event in a specific dissociation channel (left hand side). 


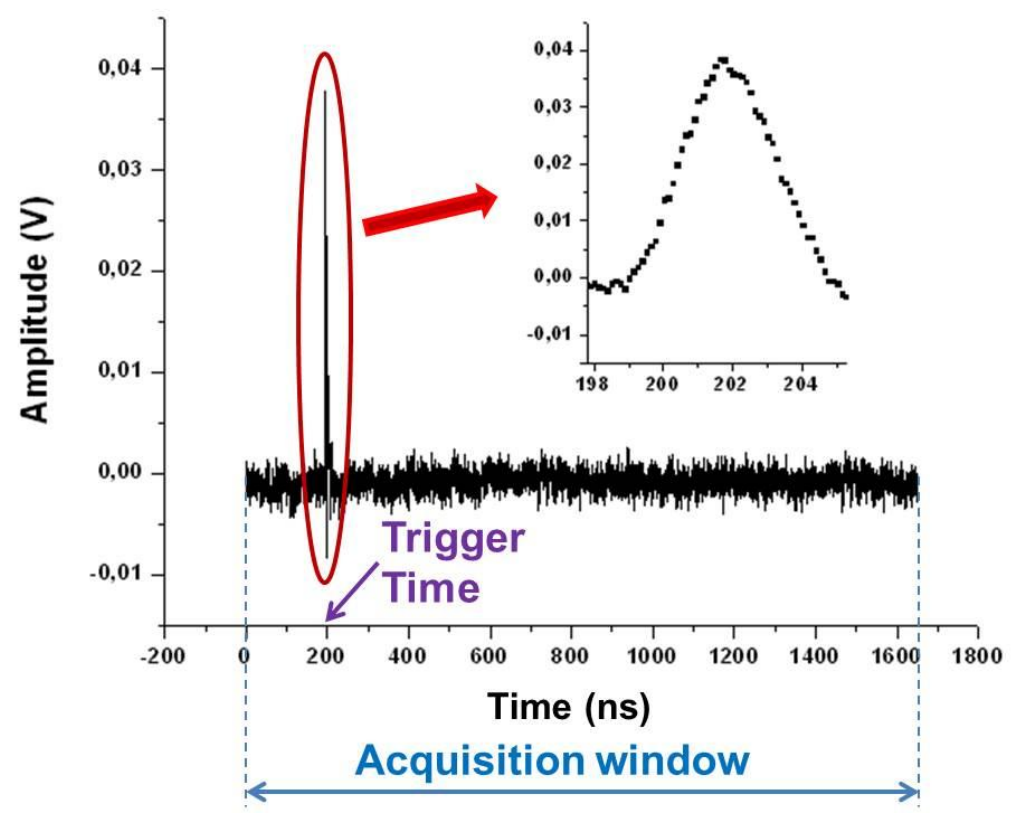

Figure 4: Signal produced from the impact of one particle on the detector by the fast ADC (8GHz/10bits) acquisition line. 


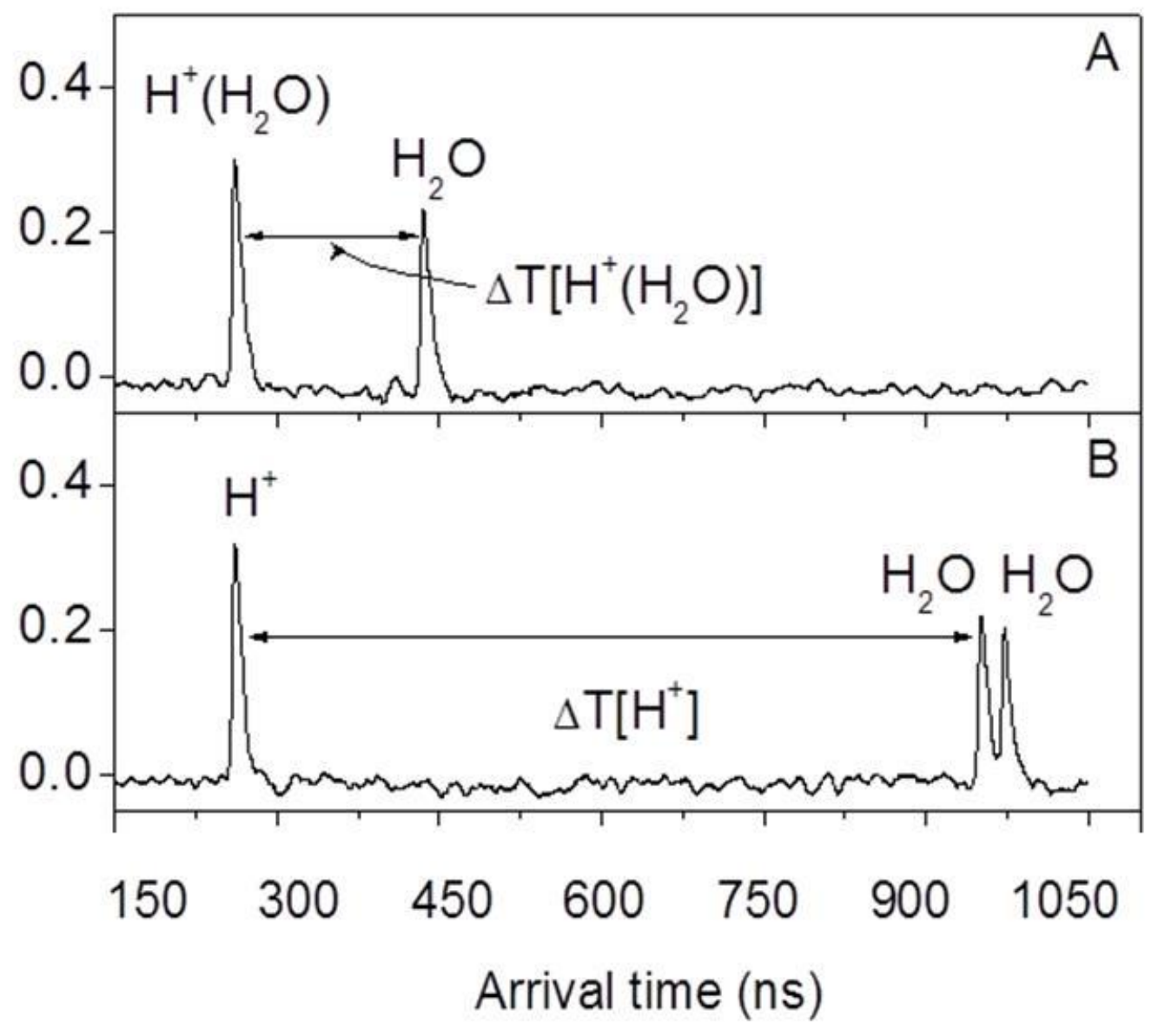

Figure 5:COINTOF arrival time spectra for $8 \mathrm{keVH}^{+}\left(\mathrm{H}_{2} \mathrm{O}\right)_{2}$ ions interacting with anArtarget beam:

(A) Detection of a $\mathrm{H}^{+}\left(\mathrm{H}_{2} \mathrm{O}\right)$ fragment ion and one neutral fragment

(B) Detection of a $\mathrm{H}^{+}$fragment ion and two neutral fragments

The time differences between the ion and the neutral(s)are in accordance with those obtained from ion trajectory simulation. 


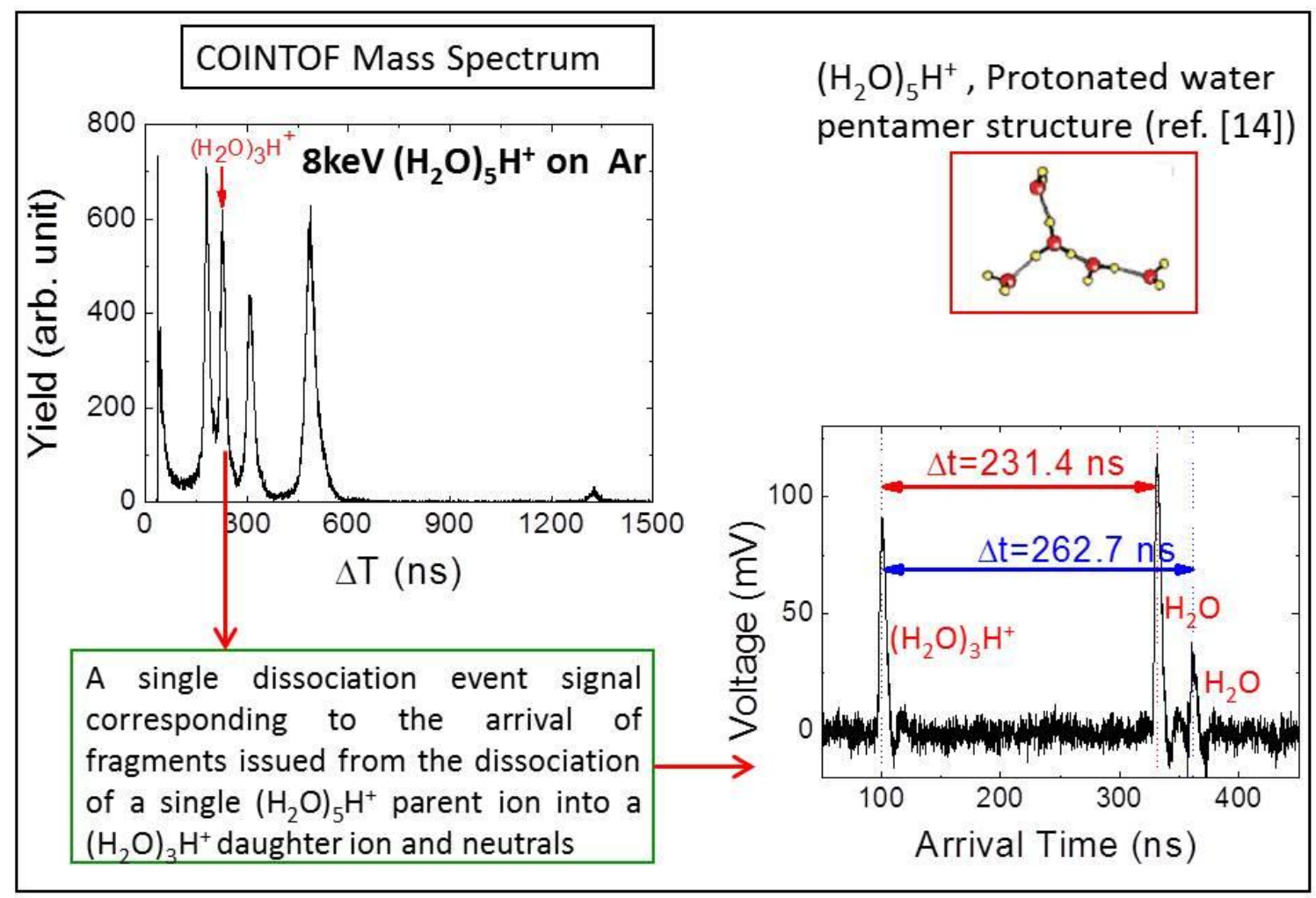

Figure 6:CID of the protonated water pentamer cluster ion

Left upper side:COINTOF mass spectrum of the charged fragments in the Collision Induced Dissociation of $8 \mathrm{keV}\left(\mathrm{H}_{2} \mathrm{O}\right)_{5} \mathrm{H}^{+}$ions with anargon gas beam

Right upper side: The most stable protonated water pentamer structure from theoretical calculations of Miyazaki et al. ${ }^{14}$.

Right lower side: A recorded single event signal for the dissociation channel $\left(\mathrm{H}_{2} \mathrm{O}\right)_{5} \mathrm{H}^{+}$into $\left(\mathrm{H}_{2} \mathrm{O}\right)_{3} \mathrm{H}^{+}+2\left(\mathrm{H}_{2} \mathrm{O}\right)$ : three peaks are observed corresponding to the three fragments. 


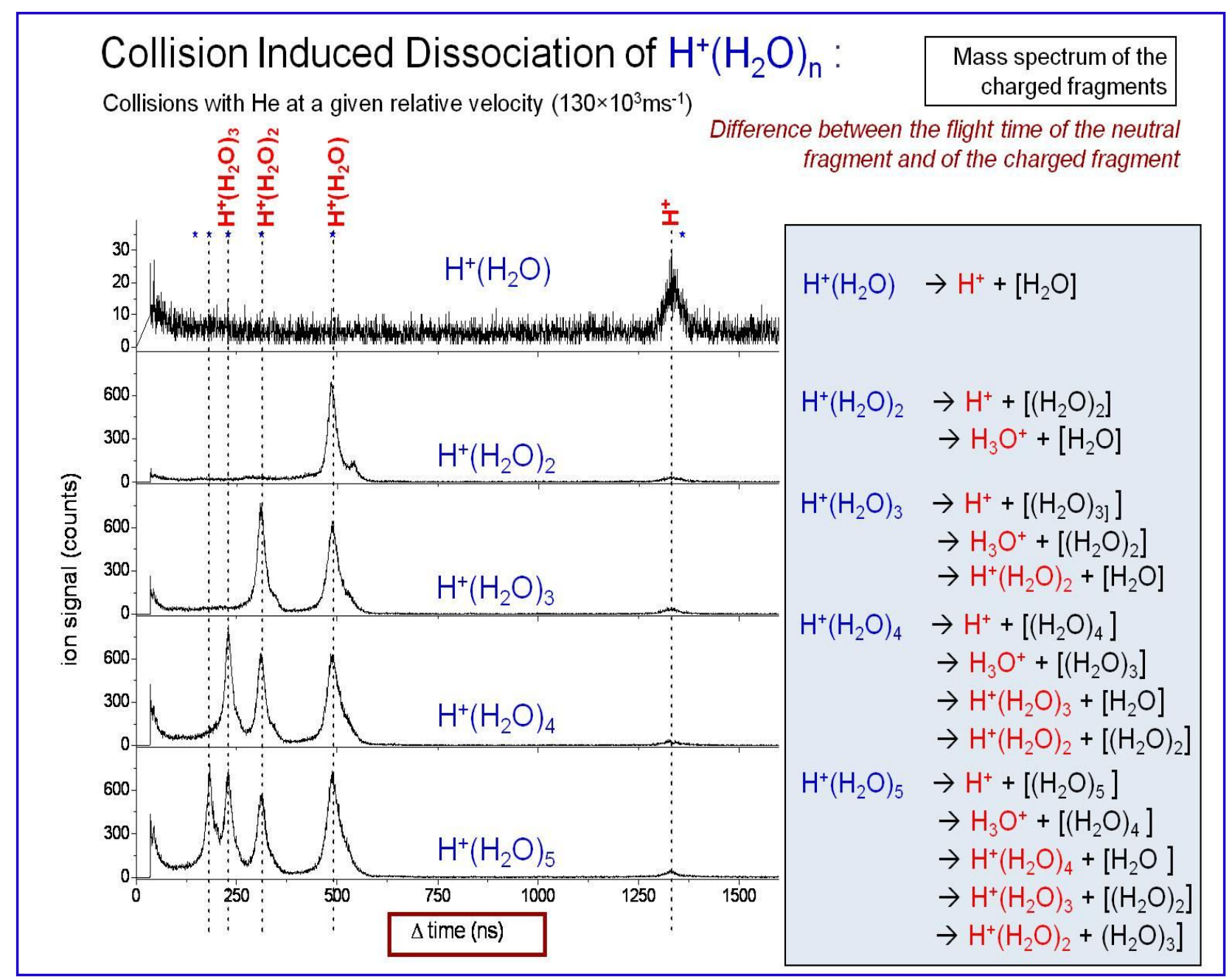

Figure 7:COINTOFmass spectraof the charged fragmentsfor $\mathrm{H}^{+}\left(\mathrm{H}_{2} \mathrm{O}\right)_{\mathrm{n}}$. parent ions with $\mathrm{n}$ from 1 to 5 The arrival time of the first neutral fragment is used as a time reference to identify the charged fragments for each of the dissociating precursor ions $\mathrm{H}^{+}\left(\mathrm{H}_{2} \mathrm{O}\right)_{\mathrm{n}}$. The red asterisks correspond to the predictions fromSIMION calculations (Table 1). All the parent ions are initially accelerated to the same velocity of $1.310^{7} \mathrm{~cm} / \mathrm{s}\left(130.10^{3} \mathrm{~m} / \mathrm{s}\right)$. The various dissociation channelsobserved are given on the right hand side. 


\section{TABLES}

\begin{tabular}{|c|c|c|c|c|c|c|}
\hline $\begin{array}{l}\text { Parent mass } \\
\text { ofprotonated } \\
\text { water cluster } \\
\text { ions(amu) }\end{array}$ & $\begin{array}{l}\text { Parent energy } \\
(\mathrm{eV})\end{array}$ & $\begin{array}{c}\text { Fragment } \\
\text { charged mass } \\
(\mathrm{amu})\end{array}$ & $\begin{array}{c}\text { Charged } \\
\text { fragment KE } \\
(\mathrm{eV})\end{array}$ & $\begin{array}{c}\text { Charged } \\
\text { fragment } \\
\text { arrival time } \\
\qquad(\mu s)\end{array}$ & $\begin{array}{l}\text { Neutral } \\
\text { fragment } \\
\text { arrival time } \\
\quad(\mu \mathrm{s})\end{array}$ & $\begin{array}{l}\text { Arrival time } \\
\text { difference } \\
\qquad \Delta \mathrm{T}(\mu \mathrm{s})\end{array}$ \\
\hline 19 & 1670.33 & 1 & 87.91210 & 0.522104 & 1.90407 & 1.381966 \\
\hline & & & & & & \\
\hline \multirow{2}{*}{37} & \multirow{2}{*}{3252.747} & 19 & 1670.329 & 1.41434 & \multirow{2}{*}{1.90407} & 0.48973 \\
\hline & & 1 & 87.91208 & 0.522104 & & 1.381966 \\
\hline & & & & & & \\
\hline \multirow{3}{*}{55} & \multirow{3}{*}{4835.165} & 37 & 3252.747 & 1.59219 & \multirow{3}{*}{1.90407} & 0.31188 \\
\hline & & 19 & 1670.329 & 1.41434 & & 0.48973 \\
\hline & & 1 & 87.91209 & 0.522104 & & 1.381966 \\
\hline & & & & & & \\
\hline \multirow{4}{*}{73} & \multirow{4}{*}{6417.582} & 55 & 4835.164 & 1.67453 & \multirow{4}{*}{1.90407} & 0.22954 \\
\hline & & 37 & 3252.747 & 1.59219 & & 0.31188 \\
\hline & & 19 & 1670.329 & 1.41434 & & 0.48973 \\
\hline & & 1 & 87.91208 & 0.522104 & & 1.381966 \\
\hline & & & & & & \\
\hline \multirow{5}{*}{91} & \multirow{5}{*}{8000} & 73 & 6417.582 & 1.72225 & \multirow{5}{*}{1.90407} & 0.18182 \\
\hline & & 55 & 4835.164 & 1.67453 & & 0.22954 \\
\hline & & 37 & 3252.747 & 1.59219 & & 0.31188 \\
\hline & & 19 & 1670.329 & 1.41434 & & 0.48973 \\
\hline & & 1 & 87.91208 & 0.522104 & & 1.381966 \\
\hline
\end{tabular}

Table 1: Arrival time differencebetween the charged fragment ionanda neutralfragmentfor different initial kinetic energies (amounting to the same initial velocity of $130.10^{3} \mathrm{~m} / \mathrm{s}$ for all parent ions studied). 


\title{
REFERENCES
}

\author{
${ }^{1}$ S. Balabanova, J. Homoki, Z. Rechtsmed 98, 235 (1987) \\ ${ }^{2}$ R. Flamini, A. Panighel, Mass. Spectrom. Rev. 25, 741 (2006) \\ ${ }^{3}$ T. Sikanen et al., Mass Spectrom. Rev. 29, 351 (2010) \\ ${ }^{4}$ B.T.Chait, Science, 314, 65 (2006) \\ ${ }^{5}$ F. Gobet, B. Farizon, M. Farizon, M.J. Gaillard, S. Louc, N. Goncalves, M. Barbatti, H. Luna, G. \\ Jalbert, N.V. de Castro Faria, M.C. Bacchus Montabonel, J.P. Buchet, M. Carré, T.D. Märk, Phys. \\ Rev. Lett. 86, 4263-4266 (2001)
}

${ }^{6}$ M.Ohkubo et al, Int.J.MassSpectrom. 299, 94 (2011)

${ }^{7}$ M. Farizon, B. Farizon, H. Abdoul-Carime, G. Bruny, S. Eden, S. Feil, C. Montano, Method for tandem time of flight analysis and analysis appliance using said method (EN). / Procédé d'analyse à temps de vol en tandem et appareil d'analyse en faisant application (FR). Université Claude Bernard Lyon 1, Dépôt de brevet n 0958991 du 15 Décembre 2009, PCT/FR2010/052733 patent ; Jul, 7 2011: WO 2011/080455.

${ }^{8}$ G. Bruny, S. Eden, S. Feil, R. Fillol, K. El Farkh, M.M. Harb, C. Teyssier, S.Ouaskit, H. AbdoulCarime, B. Farizon, M. Farizon and T.D. Märk,Review of Scientific Instruments 83 (2012) 013305

${ }^{9}$ Z. P.Wang et al., Int. J. Mass Spectrom. 285, 143-148 (2009)

${ }^{10}$ W.C. Wiley, I.H. McLaren, Time of Flight Mass Spectrometer with Improved Resolution, Review of Scientific, 26, 1150 (1955)

${ }^{11}$ B. Farizon, M. Farizon, M.J. Gaillard, E. Gerlicet S. Ouaskit, Nucl. Instr. and Meth. in Phys. Res. B 101, 287 (1995)

${ }^{12}$ Dahl DA.SIMION ${ }^{\circledR}$ 3D Version 7.0, in 50th ASMS Conference on Mass Spectrometry and Allied Topics, June 2000, Long Beach, CA; 717.

${ }^{13}$ J. Laskin, C. Lifshitz, J. Mass Spectr. 36459 (2001)

${ }^{14}$ M.Miyazaki et al. Science 304, 1134 (2004)

${ }^{15}$ J. Headrick, E. G. Diken, R. S. Walters, et al., Science 308, 1765 (2005) 